\title{
M. Kernan, R. W. Batttarbee and B. R. Moss (eds): Climate change impacts on freshwater ecosystems
}

\author{
Wiley-Blackwell, 2010, 328 pp, Hardback, £45.00, €54.00, \\ ISBN: 978-1-4051-7913-3
}

\author{
Christian Kamenik
}

Received: 2 May 2011/Accepted: 6 May 2011/Published online: 28 May 2011

(C) Springer Science+Business Media B.V. 2011

Faced with 'record breaking heat waves' in recent years it is easy for scientists, decision makers and the general public to forget that ecosystems are threatened by multiple stressors. Climate Change Impacts on Freshwater Ecosystems by Kernan et al. (2010) provides a refreshing, comprehensive and up-to-date overview that goes beyond this unidimensional view of climate change (except perhaps for Chapter 12, where Brian Moss gets carried away by the apocalyptic horsemen—but more on this later). I highly recommend this book to anyone working in the natural sciences, whether researchers, graduate students or decision makers.

The book profits from the collaborative, up-to-date knowledge gained from Euro-limpacs (a 5 year European research project with 36 partners that ended in 2009). Large parts of the book are based on the outcomes of this project, which in turn, means there is a strong focus on Europe (although there are also examples from other regions of the world). Over 328 pages and 12 chapters, 78 experts summarize their knowledge on how climate change might affect freshwater ecosystems with respect to other environmental stressors, and how this knowledge may be transferred to decision makers and the general public.

C. Kamenik $(\bowtie)$

Oeschger Centre for Climate Change Research, Institute

of Geography, University of Bern, Erlachstrasse 9a,

Trakt 3, 3012 Bern, Switzerland

e-mail: christian.kamenik@giub.unibe.ch
These experts look at the impacts of climate change on freshwater ecosystems from very different angles, incorporating different spatial and temporal scales, different methodological approaches, and different scientific fields that are not solely restricted to the natural sciences. Given the heterogeneity of the experts, the general conclusions drawn at the end of each chapter are remarkably consistent: climate change is a threat, but there are more imminent, immediate threats facing freshwater ecosystems, such as eutrophication, acidification, persistent organic pollutants (POPs) and habitat loss. All experts agreed that climate change will be a very important issue in the near future, yet how climate change will affect freshwater ecosystems is poorly understood and projections are accompanied by large uncertainties.

Chapters 1 and 2 have an introductory character. In chapter 1 the editors familiarize the reader with the climate projections of the Intergovernmental Panel on Climate Change (IPCC) Fourth Assessment Report (AR4) and ecosystem functioning and services, with a particular focus on freshwater ecosystems and their vulnerability. The editors make important references to the United Nations Millennium Ecosystem Assessment (which many people are not aware of), which began in 2001 and involved the first comprehensive assessment of ecosystem conditions and trends around the world, the services they provide, and the options for restoring, conserving or enhancing the sustainable use of ecosystems. Chapter 1 also introduces the reader to the methods and concepts of 
Euro-limpacs, and to applications that arose from improved scientific understanding, particularly with respect to the European Union Water Framework Directive (WFD). By criticizing the shortcomings of the IPCC AR4 as well as classical economic approaches, the editors make it clear they want to explore problems that reach beyond classical freshwater ecology. Chapter 2 places current climate change into a long-term perspective and stresses its dynamic nature by focusing on multi-millennial, millennial to centennial, and decadal, inter-annual and seasonal changes in temperature and effective moisture over high, mid and low latitudes, as recorded by natural climate archives, including lake sediments. This directly highlights the valuable role paleolimnology has to play in assessing and understanding climate change impacts on freshwater ecosystems.

Chapters 3 and 4 focus on abiotic aspects of climate change. Chapter 3 expands on the IPCC AR4 and deals with the direct impacts of climate change on freshwater ecosystems such as physical (e.g., thermal regime and ice cover) and chemical (mainly dissolved organic carbon) changes. Chapter 4 focuses on hydrological and morphological aspects across different spatial scales that may or may not be driven by climate change. This chapter tackles land use and restoration, highlighting how each can intensify or buffer the effects of climate change. Chapters 3 and 4 are complementary: the former focuses on lakes, the latter on streams and rivers.

Chapter 5 reassesses the use of biological indicators as early warning tools of ecosystem change with respect to climate warming, which is currently not specifically targeted in the WFD. It provides detailed lists on potential direct and indirect impacts of climate change on lakes, rivers and wetlands together with the expected responses. The authors suggest both abiotic and biotic indicators to monitor impacts on hydrology, morphology, physicochemistry and biology in cold, temperate and warm eco-regions.

Chapters 6-8 summarize the environmental problems of eutrophication, acidification and POPs, which have been major problems in the past and continue to be problematic in many regions of the world. Chapter 6 is an incredibly well written summary on eutrophication that reports results from space-fortime analysis, field (lakes, streams and wetlands) and mesocosm experiments, microevolutionary studies, paleolimnology and modeling. If you need a reason for buying this book, then here it is. Chapter 7 concentrates on how acidification studies profit (like Chapter 6) from a focus on long term monitoring data and by a strong modeling component. It provides an example of the international community coming together to successfully address a major environmental problem, which brings hope for finding a solution to dealing with climate change. However, Chapter 8, which discusses the impacts of POPs on freshwater ecosystems demonstrates our incompetence with regard to dealing with climate change: the effects are largely unknown and difficult to trace, as is making reliable predictions.

Chapters 9-11 deal with applied aspects of freshwater ecology that, more than the previous chapters focus on restoration, ecosystem modeling, management and decision making. Chapter 9 explores how to define reference conditions that are required for restoration. It provides a very positive view of paleolimnology and how to define reference conditions and detect recovery even when baseline conditions change. Chapter 10 introduces the reader to the 'Euro-limpacs modeling strategies', which aim to provide an integrated toolkit of models for catchment analysis and assessment to predict catchment-scale responses to climate change. It touches on aspects of downscaling General Circulation Models, statistical and dynamic modeling, linking different models and the large uncertainties that are still associated with the model projections. Chapter 11 takes the reader one step further to decision support systems, the problem of economic valuation, and the challenges imposed by random human behavior. It stresses the importance of transferring science into politics, and criticizes sectoralism among decision makers on the one hand and the lack of trans-disciplinarity among scientists on the other.

Now to Chapter 12 and the future. Based on the previous chapters, Brian Moss sketches the fate of freshwater ecosystems in the Arctic/Boreal zone, the mid continental latitudes, Atlantic islands, the Mediterranean and the Alps for the mid-late twenty-first century, given a projected temperature rise of $4^{\circ} \mathrm{C}$. These are dark projections. Brian Moss stresses that this chapter is the 'work of collective creative imagination'. As such, this chapter is the antipode of the previous chapters, which made down-to-earth assessments of the impacts of climate change. 
This book is not an introductory text book. It is targeted at researchers, graduate students and decision makers. Readers must link chapters themselves. For example, Chapter 2 focuses on long-term changes, while Chapter 3 has a short-term perspective. If these are read together both chapters are very comprehensive. More references among the chapters would have improved the understanding of individual chapters. In Chapter 3, for example, physical impacts were well covered while the section on chemical impacts left an ambiguous impression. This is a pity, because chemical aspects are very well covered in other parts of the book. However, each chapter can stand alone, so that readers can quickly access those parts of the book that are most relevant to them.

Overall this book provides an excellent in-depth summary on the manifold impacts of climate change on freshwater ecosystems and the depending socioeconomic systems. Much has been learnt about climate change in recent years, as demonstrated in this book by some of the best authorities in this multidisciplinary field of research. However, as the authors point out much is still unknown, particularly with regard to freshwater ecosystems, and research on climate change and its impacts is ongoing. This book makes an excellent contribution to summarizing the current state of knowledge and deserves a place on the bookshelves of natural scientists and decision makers alike.

Acknowledgments I would like to thank K. Saunders for helpful comments on an earlier version of this review. 